\title{
Effect of Potassium Deficiency on Root Growth and Nutrient Uptake in Maize (Zea mays L.)
}

\author{
Qi Du, Xinhua Zhao, Chunji Jiang, Xiaoguang Wang, Yi Han, Jing Wang, Haiqiu Yu* \\ College of Agronomy, Shenyang Agricultural University, Shenyang, China \\ Email: ^haiqiuyu@163.com
}

How to cite this paper: $\mathrm{Du}, \mathrm{Q}$., Zhao, X.H., Jiang, C.J., Wang, X.G., Han, Y., Wang, J. and Yu, H.Q. (2017) Effect of Potassium Deficiency on Root Growth and Nutrient Uptake in Maize (Zea mays L.). Agricultural Sciences, 8, 1263-1277. https://doi.org/10.4236/as.2017.811091

Received: October 17, 2017

Accepted: November 13, 2017

Published: November 16, 2017

Copyright (c) 2017 by authors and Scientific Research Publishing Inc. This work is licensed under the Creative Commons Attribution International License (CC BY 4.0).

http://creativecommons.org/licenses/by/4.0/

\begin{abstract}
Potassium $(\mathrm{K})$ is an essential nutrient on the growth and development for maize (Zea Mays L.). And the developed root morphology and root activity have great significance to nutrient absorption and play an important role in the growth and development of plants. To explore the response to K-deficiency on root growth and nutrient absorption of maize, two inbred lines, 90-21-3 (Tolerance to $\mathrm{K}$ deficiency) and D937 (Sensitive to K deficiency) were carried out to investigate the root morphology, root activity, nutrient uptake and related traits. The results showed that K-deficiency inhibited the root growth of 90-21-3 and D937, but increased the ratio of root to shoot $(\mathrm{R} / \mathrm{S})$. The total length, root surface area, the root diameter and root volume of root system of 90-21-3 and D937 were significantly decreased by K deficiency, especially the fine root $(0-0.4 \mathrm{~mm})$ in root length and root surface area. In addition, the $\mathrm{K}$ concentration of root in the two lines was significantly decreased, but root activity was significantly improved, which promoted the absorption of the root system to $\mathrm{Na}^{+}$. Compared with D937, 90-21-3 was able to distribute more carbohydrates from shoot to the root system under $\mathrm{K}$ deficiency, alleviating the inhibition of root growth. The fine root system was the main part for absorption nutrient. The length and surface area of 90-12-3 were no difference, and significantly decreased by $12.90 \%$ and $17.65 \%$ in D 937 after $5 \mathrm{~d}$ of K deficiency. As well, the root activity of 90-21-3 was significantly increased when encountered to $\mathrm{K}$ deficiency, which promoted the accumulation of $\mathrm{Na}^{+}$and $\mathrm{Ca}^{2+}$ and regulated the osmotic stress. Therefore, it could be a responding mechanism for tolerance crop by maintaining large root system, increasing root activity and adjusting nutrient absorption to adapt to K deficiency.
\end{abstract}

\section{Keywords}

Maize, K Deficiency, Root Morphology, Root Activity, Nutrient Absorption 


\section{Introduction}

$\mathrm{K}^{+}$is one of the essential macronutrients for plant growth and development. Additionally, $\mathrm{K}$ plays an important role in the biophysical and biochemical cellular functions involved in osmoregulation, photosynthesis, electrical neutralization, transport of metabolites, and enzyme activation in living plant cells [1] [2]. However, compared with nitrogen $(\mathrm{N})$ and phosphorus $(\mathrm{P}), \mathrm{K}$ is applied at a lower level [3], only meeting $20 \%-33 \%$ of growth and developmental needs in maize [4]. Since the late 1990s, there has a negative trend of K balance about 60 $\mathrm{kg} \mathrm{ha}^{-1} \mathrm{year}^{-1}$ in intensive agricultural production condition due to improper fertilizing in China [5]. Currently, more than $2 / 3$ large agricultural areas of China were reported to be deficient in $\mathrm{K}$ availability (less than $100 \mathrm{mg} / \mathrm{kg}$ ) or severe deficiency (less than $50 \mathrm{mg} / \mathrm{kg}$ ), which severely restricts the growth and production of crops [6]. Therefore, it is of great significance to excavate potassium efficient genotype crops and alleviate the status of effective potassium in soil by mobilizing its own biological potential and improving the utilization of soil potassium.

Maize is the largest grain crop in China and high demand for potash, especially in the northeast area. Root system is the main organ for nutrient uptake. And ideal root morphology and activity were great significance to nutrient absorption from soil, which play an important role in the growth and development for crops [7]. The morphology and structure of root system were adjusted for absorption of surrounding nutrients under nutrient stress [8] [9]. For example, K-efficient genotypes in rice often have larger root system than K-inefficient genotypes, which showed well-developed root, stronger absorption and large interface between root and soil [10] [11]. Higher root activity could permit crops to acquire largely nutrient from soil, especially under abiotic stress. The root in different diameters was great differences in capacity for nutrient uptake, stronger in fine roots than coarse roots [12]. Various nutrient elements in plants were interrelationship with potassium, such as N, P, Na and Ca, etc. [13]. Studies have shown that different genotypes rice accumulation of potassium and dry matter was depressed under low $\mathrm{K}$ stress, but significantly increased the potassium use efficiency and $\mathrm{Na}^{+}$accumulation, eventually increased the ratio of $\mathrm{Na}^{+}$to $\mathrm{K}^{+}$ [14]. Meanwhile, $\mathrm{Ca}^{2+}$ could promote the absorption of $\mathrm{K}^{+}$by regulating the potassium channel protein AKT1 [15] [16] [17]. It is well-known that seedling stage is a sensitive period for maize to be deficient in potassium. The objectives of this study were to investigate the effects of $\mathrm{K}$ deficiency on root configuration and nutrient absorption at seedling stage and to explore the different response to $\mathrm{K}$ deficiency in 90-21-3 and D937 on root morphology, root activity and nutrient absorption, in order to provide theoretical basis and further clarify the physiological mechanism to K deficiency.

\section{Materials and Methods}

\section{Plant material and experimental design}

Maize seeds (Zea mays. L.) of 90-21-3 (Tolerance to potassium deficiency) 
and D937 (Sensitive to potassium deficiency) were screened out by field, pool and hydroponics experiment for years in low potassium soil of Liaozhong county, China [18]. The genotype 90-21-3 showed no symptoms of K deficiency, but leaf margin chlorosis was significantly performed in D937 at the seedling stage (Figure 1).

The study was performed using the hydroponic planting method in Shenyang Agricultural University, Liaoning province, China. Full and uniform seeds were disinfected in $7 \% \mathrm{NaClO}_{3}$ solution and washed for 3 times with deionized water before sowing. The seeds were primarily germinated in silica sand on July 12 , 2016 and carefully transplanted into an opaque plastic box $(50 \mathrm{~cm} \times 35 \mathrm{~cm} \times 15$ $\mathrm{cm}$ ) containing $22 \mathrm{~L}$ nutrient solution until development of two visible leaves (July, 18) without endosperm, in a rainproof greenhouse under a natural environment. The nutrient solution was 1/2 Hoagland's nutrient solution and Arnon microelements modified from Cao et al. (2007) [18], and containing: $2000 \mu \mathrm{mol}$

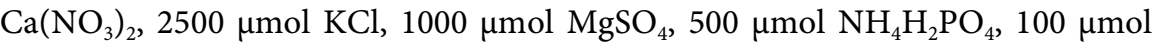
EDTA-Fe, $115 \mu \mathrm{mol} \mathrm{H}_{3} \mathrm{BO}_{3}, 22.5 \mu \mathrm{mol} \mathrm{MnCl}_{2}, 0.16 \mu \mathrm{mol} \mathrm{CuSO}_{4}, 0.75 \mu \mathrm{mol}$ $\mathrm{ZnSO}_{4}$, and $0.182 \mu \mathrm{mol}\left(\mathrm{NH}_{4}\right)_{6} \mathrm{Mo}_{7} \mathrm{O}_{24}$. The $\mathrm{pH}$ of the nutrient solution was adjusted to 6.0 by addition of $0.1 \mathrm{~mol} \mathrm{~L}^{-1} \mathrm{NaOH}$ or $\mathrm{HCl}$ and renewed once every seven days. Air was pumped into the culture solution to provide oxygen for roots, at a rate of $40 \mathrm{~min} \mathrm{~h}^{-1}$. For $\mathrm{K}$ starvation, 7-day-old plants were transferred for 1, 3, 5, or 7 days to a K-deficient nutrient solution. To maintain the stability of $\mathrm{K}^{+}$supply during plant growth, the $\mathrm{K}^{+}$concentration in culture solution was monitored daily and replenished to $2.5 \mathrm{mmol} \mathrm{L}^{-1}$.

\section{Plant performance}

Four uniformed seedlings each treatment were harvested separately at each time point as described above and washed with deionized water. And roots and shoots were detached from the upper crown root, and baked at $105^{\circ} \mathrm{C}$ for $15 \mathrm{~min}$ and then dried at $70^{\circ} \mathrm{C}$ to constant weight. The root to shoot ratio (R/S) was based on ratio of root dry weight to shoot dry weight.

\section{Root activity determination}

Root activity measurement was performed according to Luo et al. (2016) with

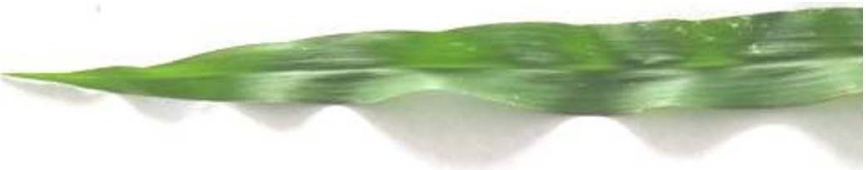

$90-21-3$

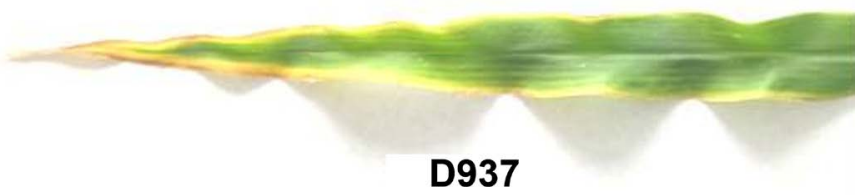

Figure 1. Comparison of leaf blade between 90-21-3 and D937 under K deficiency at seedling stage. 
triphenyl tetrazolium chloride (TTC) method [19]. Approximately $0.3 \mathrm{~g}$ roots were placed in tubes filled with $5 \mathrm{~mL}$ of $0.4 \%$ TTC and $5 \mathrm{~mL}$ of phosphate buffer $(1 / 15 \mathrm{~mol} / \mathrm{L}, \mathrm{pH} 7.0)$, keep at $37^{\circ} \mathrm{C}$ for $1 \mathrm{~h}$, then add $2 \mathrm{~mL}$ sulfuric acid $(1 \mathrm{~mol} / \mathrm{L})$ into the tubes to terminate reaction. The red triphenyl formazan (TTF) was extracted by ethyl acetate, and the absorbance was measured at $485 \mathrm{~nm}$ with an UV-spectrophotometer (Hitachi UV-1800, Japan). The activity was calculated by the standard curve prepared with known TTF concentrations.

\section{Root configuration}

Four uniformed seedlings each treatment were scanned with an EPSON Transparency unit and then analyzed with WinRhizo Program (Regent Instruments Inc. Canada). The root sample was placed in a glass rectangle sink (300 $\mathrm{mm} \times 200 \mathrm{~mm} \times 20 \mathrm{~mm}$ ) with about $8-10 \mathrm{~mm}$ deep layer of water to extend fully and minimize root overlap for capturing image. Total root length, total surface area, total volume and average diameter were acquired by analysis of root image. Fine roots are commonly considered be stronger capacity to nutrient and/or water than coarse roots. Referred to the results of previous studies on maize seedling [20] and based on average diameter of the experiment, we classified total roots into 3 groups: fine roots with average diameter less than $0.4 \mathrm{~mm}$, middle roots with average diameter between $0.4 \mathrm{~mm}$ and $0.8 \mathrm{~mm}$, and coarse roots with average diameter larger than $0.8 \mathrm{~mm}$.

\section{Nutrient determination}

The dry power of root and shoot was digested by $\mathrm{H}_{2} \mathrm{SO}_{4}$ at $380^{\circ} \mathrm{C}$ for $1.5 \mathrm{~h}$, and then clarified with drops of $30 \% \mathrm{H}_{2} \mathrm{O}_{2}$. The clarified sulphate acid was cooled to room temperature and dilute with deionized water to $100 \mathrm{ml}$. N was measured by Kjeldahl method, and $\mathrm{P}$ was measured by vanadium molybdate yellow colorimetric method according to Bao (2005) [21]. K, Na, and $\mathrm{Ca}$, analyses were conducted after digestion by $\mathrm{HNO}_{3}-\mathrm{H}_{2} \mathrm{O}_{2}$ using a flame photometer (Sherwood M410, UK).

\section{Statistical analysis}

All dates were compared with SPSS18.0 software (SPSS Inc., Chicago, IL, USA). Differences between treatments were considered significant at a 0.05 level of probability according to least significant difference (LSD) tests. The figures were plotted using Origin version 9.0 software. The data are presented as means \pm SD.

\section{Results}

\subsection{Plant Performance}

The accumulation of dry matter of 90-21-3 and D937 was reduced after K starvation, and more decrease in shoot than root (Figure 2). Compared with the controls, the total dry weight of 90-21-3 was significantly decreased $12.62 \%$, and $27.83 \%$ in D937. The root and shoot weight were in no difference after $1 \mathrm{~d}$ and 3 $\mathrm{d}$ of $\mathrm{K}$ deficiency, but significantly decreased at $5 \mathrm{~d}$ and $7 \mathrm{~d}$. The 90-21-3 was significantly decreased by $12.09 \%$ and $13.15 \%$ in shoot, $5.36 \%$ and $7.90 \%$ in root 


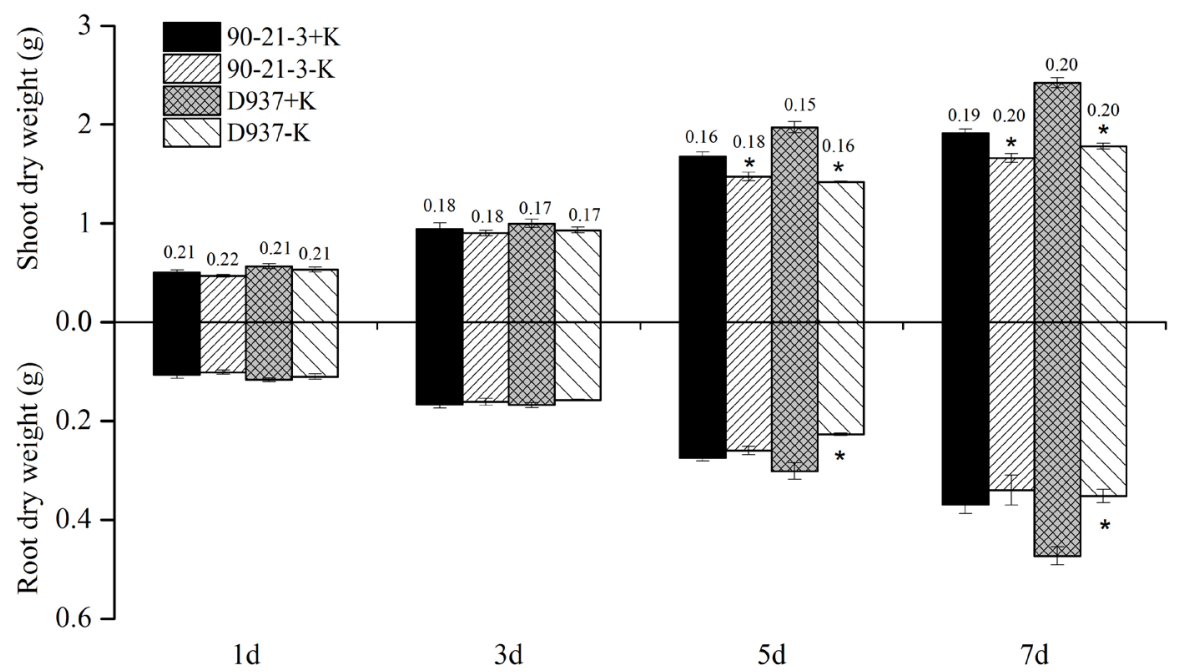

Note: ${ }^{\star}$ represent significant differences for the same genotype between $\mathrm{K}$ deficiency and CK at $5 \%$ level. Each figure on the histogram was presented the R/S. Values are expressed as means of 4 replicates and the bars indicate the standard errors, the same as below.

Figure 2. Effect of potassium deficiency on dry weight of different maize genotypes.

at $5 \mathrm{~d}$ and $7 \mathrm{~d}$ of $\mathrm{K}$ deficiency. The D937 was significantly decreased by $24.68 \%$ and $25.59 \%$ in root of D937, 28.17\% and 26.54\% in shoot at $5 \mathrm{~d}$ and $7 \mathrm{~d}$ of $\mathrm{K}$ deficiency. But, the R/S of both was tendency to increase with time of $\mathrm{K}$ deficiency. The ratio was significantly increased by $20.07 \%$ and $23.23 \%$ after $5 \mathrm{~d}$ and $7 \mathrm{~d}$ of $\mathrm{K}$ deficiency, while no difference in $\mathrm{D} 937$.

\subsection{Root Configuration of Maize Seedlings}

The total length and total surface area of the root system are closely related to the absorption capacity of the root system [22]. Compared with the control, the total root length, total surface area, total volume and average diameter of 90-21-3 and D937 were decreased under K deficiency treatments (Table 1). After $5 \mathrm{~d}$ of $\mathrm{K}$ deficiency, the root length and surface area were decreased by $3.76 \%$ and $3.07 \%$, but significantly decreased by $19.90 \%$ and $13.41 \%$ in average diameter and total volume. The total length, total surface area and total volume of D937 were significantly reduced by $10.53 \%, 11.25 \%$ and $14.06 \%$, respectively. Compared with the controls, the 90-21-3 was significantly decreased by $9.36 \%$, $6.96 \%, 25.22 \%$ and $14.05 \%$ in root length, surface area, average diameter and root volume at $7 \mathrm{~d}$ of $\mathrm{K}$ deficiency, respectively, and 19.21\%, 17.23\%, $11.69 \%$ significantly decreased in root length, surface area and root volume of D937 although no difference in average diameter.

\subsection{Growth of Seedling Roots with Different Diameters}

\subsubsection{Root Length}

The root in different diameters was great differences in capacity for nutrient uptake, stronger in fine roots than coarse roots [12]. The fine root length was the largest proportion in the total root length, but decreased in fine root, middle 
Table 1. Varieties of K deficiency on root parameters of different maize genotypes.

\begin{tabular}{|c|c|c|c|c|c|c|c|c|}
\hline & \multicolumn{4}{|c|}{ Total root length $(\mathrm{cm})$} & \multicolumn{4}{|c|}{ Total root surface area $\left(\mathrm{cm}^{2}\right)$} \\
\hline & $1 \mathrm{~d}$ & $3 \mathrm{~d}$ & $5 \mathrm{~d}$ & $7 \mathrm{~d}$ & $1 \mathrm{~d}$ & $3 \mathrm{~d}$ & $5 \mathrm{~d}$ & $7 \mathrm{~d}$ \\
\hline $90-21-3+\mathrm{K}$ & $109.5 \pm 4.74 \mathrm{ab}$ & $122 \pm 2.49 \mathrm{~b}$ & $154.83 \pm 8.17 \mathrm{bc}$ & $187.24 \pm 5.45 b$ & $108.17 \pm 3.54 \mathrm{a}$ & $133.03 \pm 5.93 b$ & $172.17 \pm 10.7 \mathrm{~b}$ & $235.23 \pm 5.54 \mathrm{~b}$ \\
\hline $90-21-3-\mathrm{K}$ & $112.35 \pm 2.81 \mathrm{a}$ & $128 \pm 3.77 \mathrm{~b}$ & $149 \pm 2.92 \mathrm{c}$ & $177.89 \pm 7.62 \mathrm{c}$ & $107.93 \pm 4.16 \mathrm{a}$ & $129.96 \pm 6.52 b$ & $166.88 \pm 9.34 b$ & $218.86 \pm 4.04 \mathrm{c}$ \\
\hline $\mathrm{D} 937+\mathrm{K}$ & $96.22 \pm 2.3 b$ & $144 \pm 3.31 \mathrm{a}$ & $191 \pm 6.86 \mathrm{a}$ & $219.39 \pm 4.93 \mathrm{a}$ & $104.03 \pm 3.75 a$ & $159.72 \pm 2.97 \mathrm{a}$ & $211.59 \pm 9.07 \mathrm{a}$ & $274.1 \pm 8.15 \mathrm{a}$ \\
\hline \multirow[t]{3}{*}{ D937-K } & $103.04 \pm 1.87 \mathrm{~b}$ & $141.07 \pm 3.62 \mathrm{a}$ & $170.89 \pm 3.71 b$ & $177.25 \pm 10.79 c$ & $104.83 \pm 4.38 \mathrm{a}$ & $146.31 \pm 3.94 b$ & $187.79 \pm 6.23 b$ & $226.89 \pm 16.79 b c$ \\
\hline & \multicolumn{4}{|c|}{ Average root diameter $(\mathrm{mm})$} & \multicolumn{4}{|c|}{ Total root volume $\left(\mathrm{cm}^{3}\right)$} \\
\hline & $1 \mathrm{~d}$ & $3 \mathrm{~d}$ & $5 \mathrm{~d}$ & $7 \mathrm{~d}$ & $1 \mathrm{~d}$ & $3 \mathrm{~d}$ & $5 \mathrm{~d}$ & $7 \mathrm{~d}$ \\
\hline $90-21-3+K$ & $0.37 \pm 0.02 \mathrm{a}$ & $0.37 \pm 0 \mathrm{~b}$ & $0.44 \pm 0.01 \mathrm{a}$ & $0.48 \pm 0.02 \mathrm{a}$ & $1.72 \pm 0.09 \mathrm{a}$ & $2.39 \pm 0.03 b c$ & $3.02 \pm 0.12 b$ & $4.88 \pm 0.18 \mathrm{ab}$ \\
\hline $90-21-3-\mathrm{K}$ & $0.36 \pm 0.02 \mathrm{a}$ & $0.32 \pm 0.02 b$ & $0.35 \pm 0.01 \mathrm{c}$ & $0.36 \pm 0.01 b$ & $1.65 \pm 0.12 \mathrm{a}$ & $2.09 \pm 0.08 c$ & $3.01 \pm 0.1 \mathrm{c}$ & $4.19 \pm 0.04 c$ \\
\hline D937+K & $0.36 \pm 0.01 \mathrm{a}$ & $0.4 \pm 0.01 \mathrm{a}$ & $0.39 \pm 0.01 b$ & $0.47 \pm 0.02 \mathrm{a}$ & $1.89 \pm 0.13 a$ & $2.88 \pm 0.02 \mathrm{a}$ & $3.97 \pm 0.1 \mathrm{a}$ & $5.33 \pm 0.13 a$ \\
\hline D937-K & $0.39 \pm 0.02 \mathrm{a}$ & $0.38 \pm 0.01 \mathrm{ab}$ & $0.41 \pm 0.02 \mathrm{ab}$ & $0.45 \pm 0.02 \mathrm{a}$ & $1.81 \pm 0.17 \mathrm{a}$ & $2.58 \pm 0.04 \mathrm{ab}$ & $3.41 \pm 0.08 \mathrm{~b}$ & $4.7 \pm 0.2 b$ \\
\hline
\end{tabular}

Note: Values are expressed as means \pm SE with 4 replicates. Significant differences $(p<0.05)$ between days and treatments are indicated by different letters.

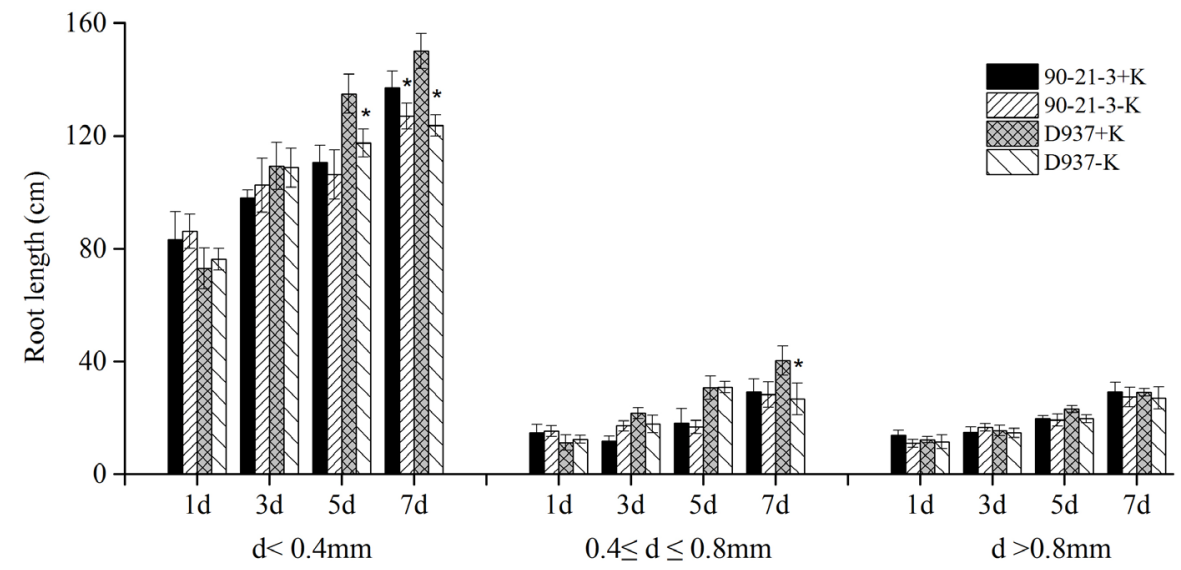

Note: ${ }^{\star}$ represent significant differences for the same genotype between $\mathrm{K}$ deficiency and CK at $5 \%$ level.

Figure 3. Varieties of K deficiency on root length among genotypes with different root diameter ranges.

root and coarse root after treatment of $\mathrm{K}$ deficiency (Figure 3). Compared with the control, 90-21-3 was slightly decreased after $7 \mathrm{~d}$ of $\mathrm{K}$ deficiency, and no difference in middle and coarse root. The fine root and middle root of D937 were significantly decreased by $17.65 \%$ and $33.81 \%$ after $7 \mathrm{~d}$ of $\mathrm{K}$ deficiency, but no affect on coarse root.

\subsubsection{Root Surface Area}

The fine and coarse root surface area of 90-21-3 and D937 were main part in total root surface area (Figure 4). The 90-21-3 was significantly increased $8.96 \%$ after $3 \mathrm{~d}$ of K deficiency, but significantly decreased of 9.05\% in D937. After $7 \mathrm{~d}$ of $\mathrm{K}$ deficiency, the surface area of D937 was decreased $24.15 \%, 31.17 \%$ and $13.33 \%$ in the three types root, respectively, and little affect on 90-21-3. 


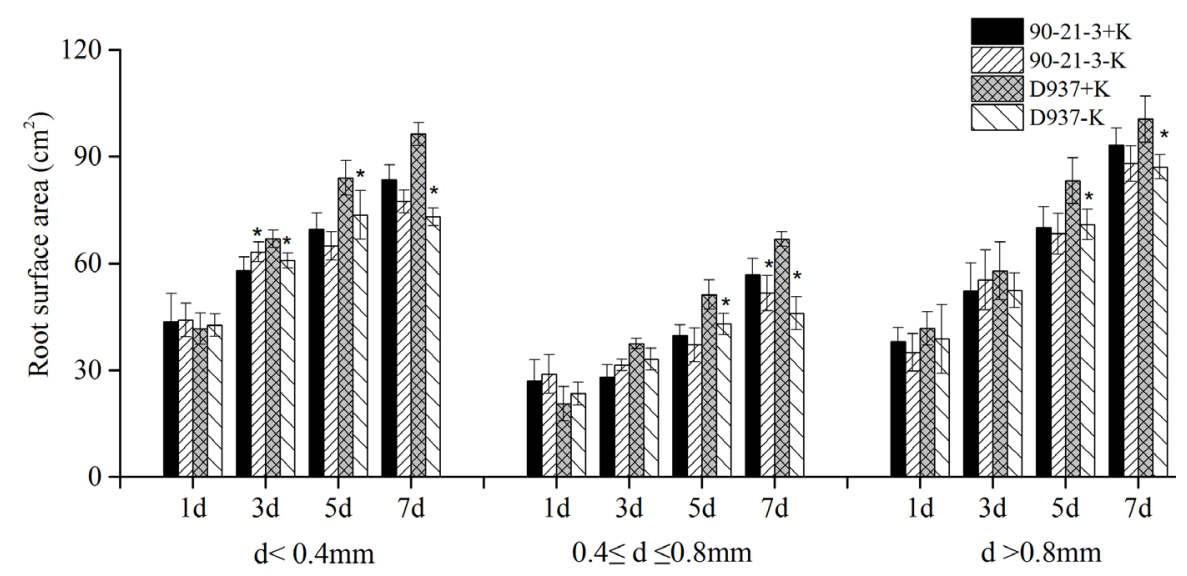

Figure 4. Varieties of K deficiency on root surface area among genotypes with different root diameter ranges.

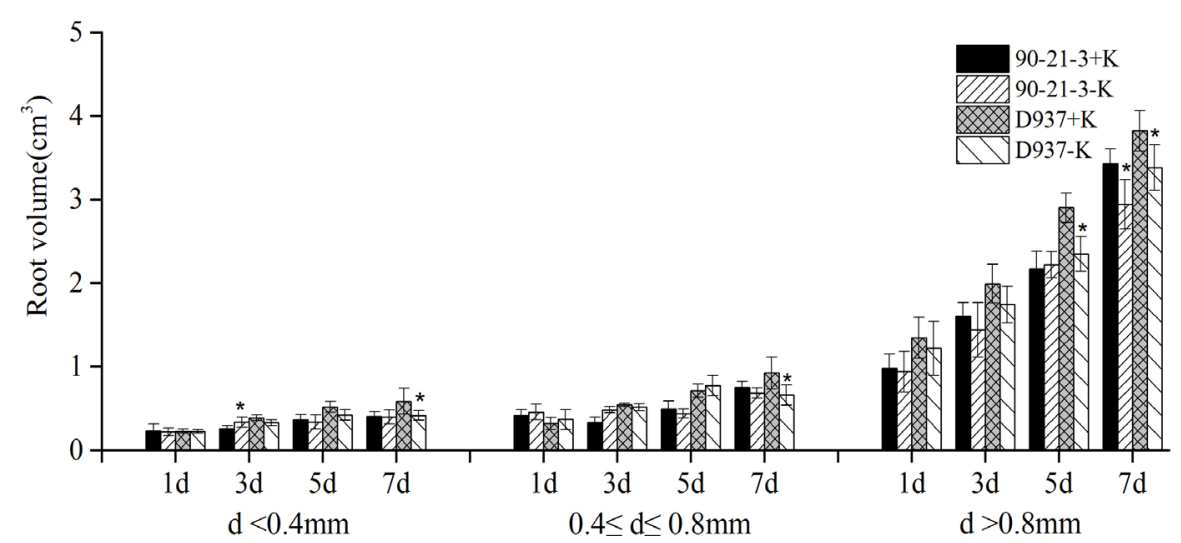

Figure 5. Varieties of potassium deficiency on root volume among genotypes with different root diameter ranges.

\subsubsection{Root Volume}

As shown in Figure 5, the coarse root volume of 90-21-3 and D937 was larger ratio in the total volume of the root than fine root and middle root. The D937 were significantly decreased by $28.99 \%$ and $28.52 \%$ in fine and middle root, respectively, and little decreased in 90-21-3 until $7 \mathrm{~d}$ of $\mathrm{K}$ deficiency. And the coarse root of $90-21-3$ and D937 were significantly decreased by $14.29 \%$ and $11.53 \%$ in comparison to the controls.

\subsection{Root Activity}

The dynamic changes of root system were shown in Figure 6. The activity of 90-21-3 and D937 is relatively stable in the controls, but significantly varied with time of $\mathrm{K}$ deficiency treatments. Compared with the controls, the activity of 90-21-3 was significantly enhanced by $19.09 \%, 18.21 \%, 46.04 \%$ and $67.30 \%$ after $1 \mathrm{~d}, 3 \mathrm{~d}, 5 \mathrm{~d}$, or $7 \mathrm{~d}$ of $\mathrm{K}$ deficiency. Differed from 90-21-3 under K deficiency treatment, the activity of D937 were significantly decreased by $22.17 \%$ and $35.24 \%$ at $1 \mathrm{~d}$ and $3 \mathrm{~d}$, and then significantly increased by $28.69 \%$ and $29.24 \%$ at $5 \mathrm{~d}$ and $7 \mathrm{~d}$ in comparison to the controls. 


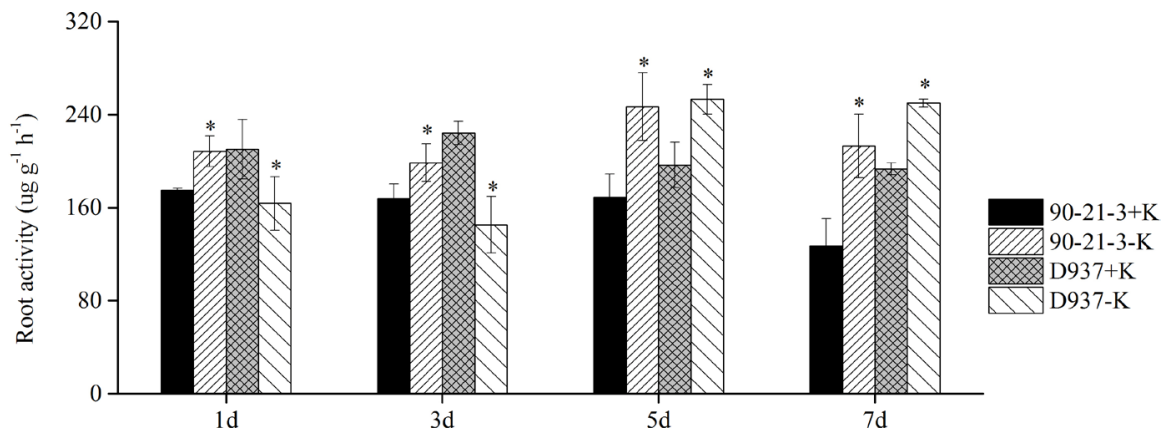

Figure 6. Varieties of potassium deficiency on root activity of different maize genotypes.

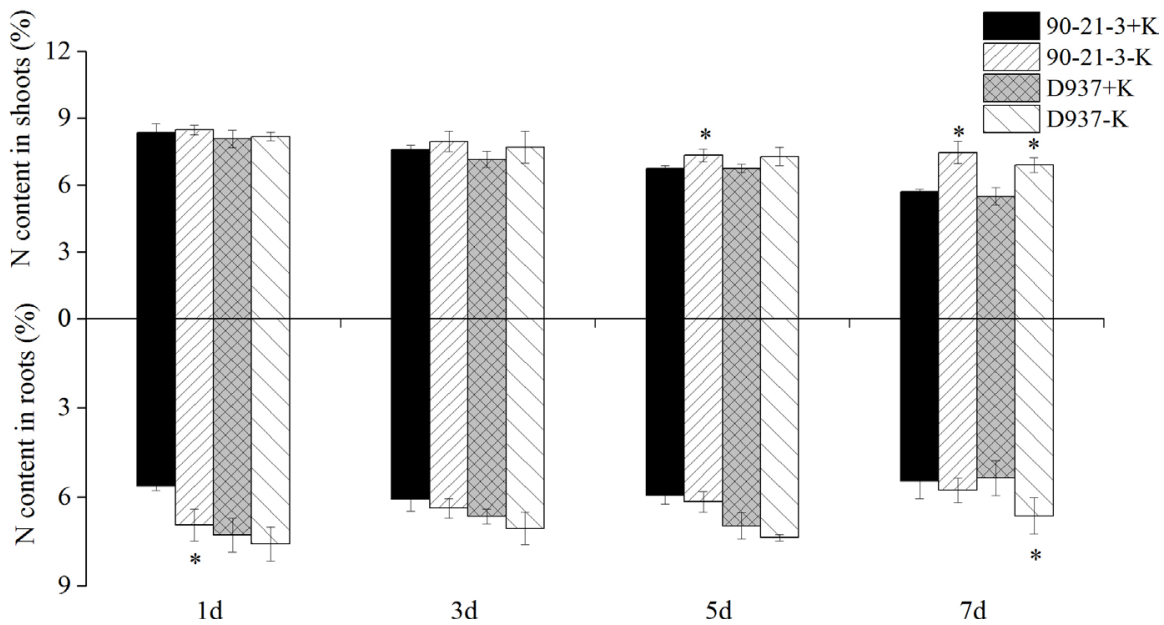

Figure 7. Effect of potassium deficiency on $\mathrm{N}$ content of different maize genotypes.

\subsection{Nutrient Uptake of Maize Seedling}

$\mathrm{N}$ content As shown in Figure 7, the $\mathrm{N}$ content in the root of 90-21-3 and D937 roots was relatively stable with time of $\mathrm{K}$ deficiency, but significantly increased in shoots. After $5 \mathrm{~d}$ of $\mathrm{K}$ deficiency, the $\mathrm{N}$ in shoot of 90-21-3 was largely accumulated in 90-21-3. Compared with controls, more than $30.87 \%$ and $25.60 \% \mathrm{~N}$ were accumulated in 90-21-3 and D937 after $7 \mathrm{~d}$ of $\mathrm{K}$ deficiency.

P content As shown in Figure 8, the P in root of 90-21-3 and D937 were significantly affected by $\mathrm{K}$ deficiency, and no difference in shoots. The $\mathrm{P}$ in roots of 90-21-3 was largely accumulated, $27.44 \%$ and $30.48 \%$ after $1 \mathrm{~d}$ and $3 \mathrm{~d}$ of K deficiency, inversely, significantly decreased of $17.99 \%$ and $16.62 \%$ at $5 \mathrm{~d}$ and $7 \mathrm{~d}$ in comparison to the control. The D937 were slightly increased at $1 \mathrm{~d}$ and $3 \mathrm{~d}$ of $\mathrm{K}$ deficiency, but significantly reduced by $34.39 \%$ and $14.61 \%$ after $5 \mathrm{~d}$ and $7 \mathrm{~d}$ of $\mathrm{K}$ deficiency, respectively.

$\mathrm{K}$ content Compared with the control, the K-deficient treatment significantly reduced the content of $\mathrm{K}^{+}$in the shoots and roots of the two inbred lines, and accumulated higher $\mathrm{K}$ in shoot than root (Figure 9). Under $\mathrm{K}$ deficiency, the $\mathrm{K}^{+}$ of $90-21-3$ was significantly decreased by $12.37 \%, 38.34 \%, 48.34 \%$ and $48.25 \%$ in shoots, and reduction of $32.52 \%, 68.42 \%, 55.65 \%, 41.25 \%$ and $44.76 \%$ in roots. The D937 were significantly reduced by $15.60 \%, 40.32 \%, 51.06 \%$ and $52.64 \%$ in 


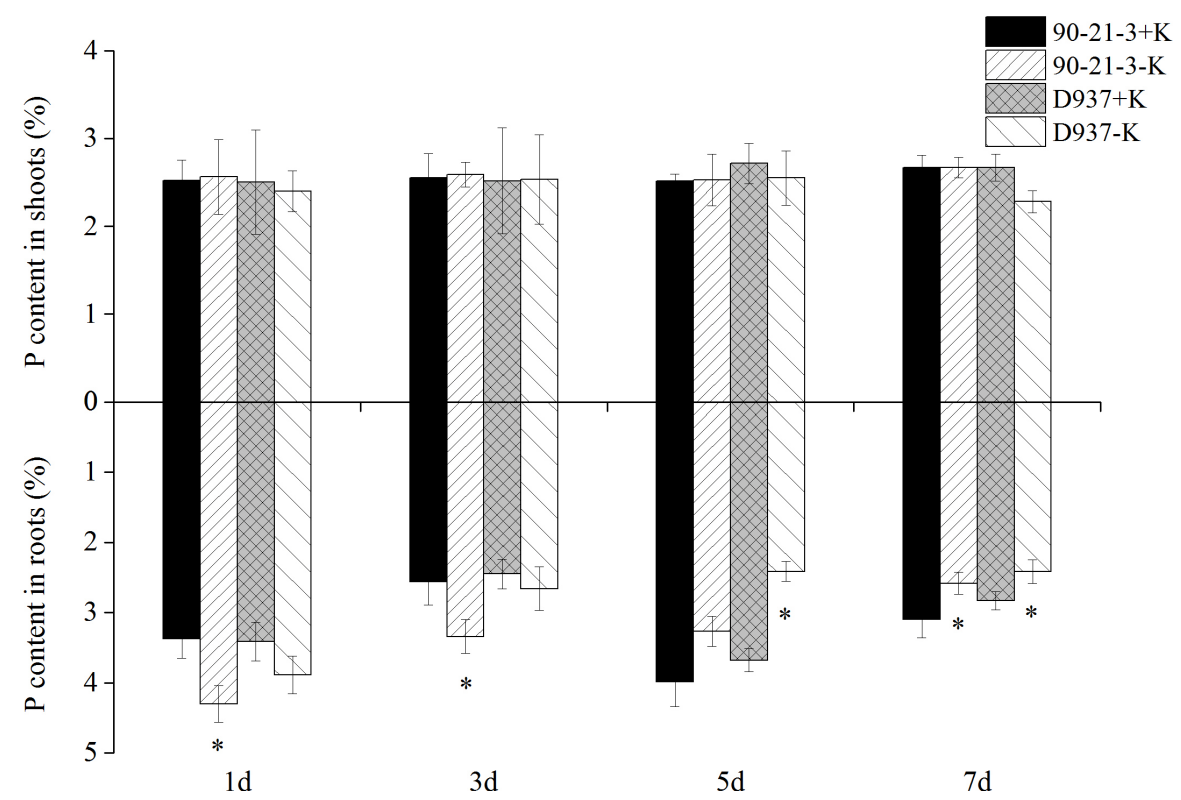

Figure 8. Effect of potassium deficiency on P content of different maize genotypes.

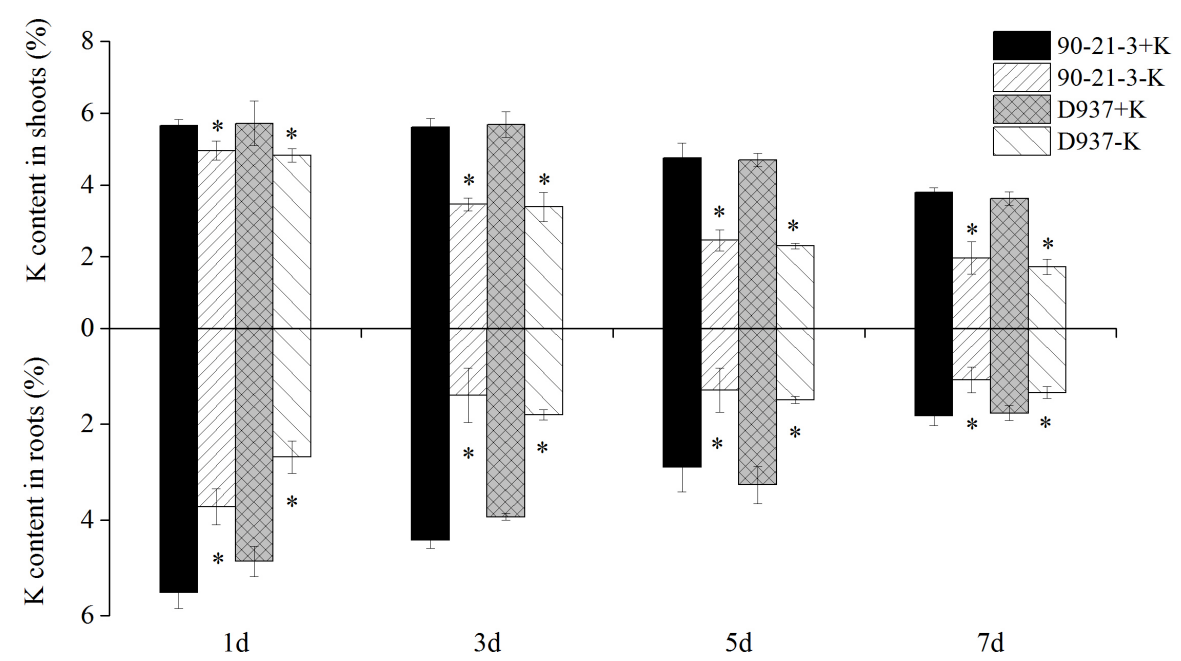

Figure 9. Effect of potassium deficiency on K content of different maize genotypes.

shoots, and reduction of $44.76 \%, 54.19 \%, 54.41 \%$ and $24.39 \%$ in roots.

$\mathrm{Na}$ content As shown in Figure $10, \mathrm{Na}^{+}$was more accumulated in roots than shoot both treatments and controls. Compared with the controls, $\mathrm{Na}$ in shoots of 90-21-3 and D937 were in no difference, but significantly accumulated in root. Distinctly, $\mathrm{Na}^{+}$in root of 90-21-3 significantly increased by $67.22 \%, 181.58 \%$ and $19.33 \%$ after $1 \mathrm{~d}, 3 \mathrm{~d}$ and $5 \mathrm{~d}$ of $\mathrm{K}$ deficiency in comparison to the controls. Compared with the controls, $\mathrm{Na}^{+}$in D937 were significantly increased by $105.60 \%$ and 55.64 at $3 \mathrm{~d}$ and $5 \mathrm{~d}$ of $\mathrm{K}$ deficiency, but slightly decreased at $1 \mathrm{~d}$.

Ca content As shown in Figure 11, the $\mathrm{Ca}^{2+}$ content of root were in no difference, and promoted in shoots under K deficiency treatments. Compared with the controls, the $\mathrm{Ca}^{2+}$ content in shoots of 90-21-3 was significantly increased by $18.92 \%$ and $48.28 \%$ after $5 \mathrm{~d}$ and $7 \mathrm{~d}$ of $\mathrm{K}$ deficiency, respectively, and little 


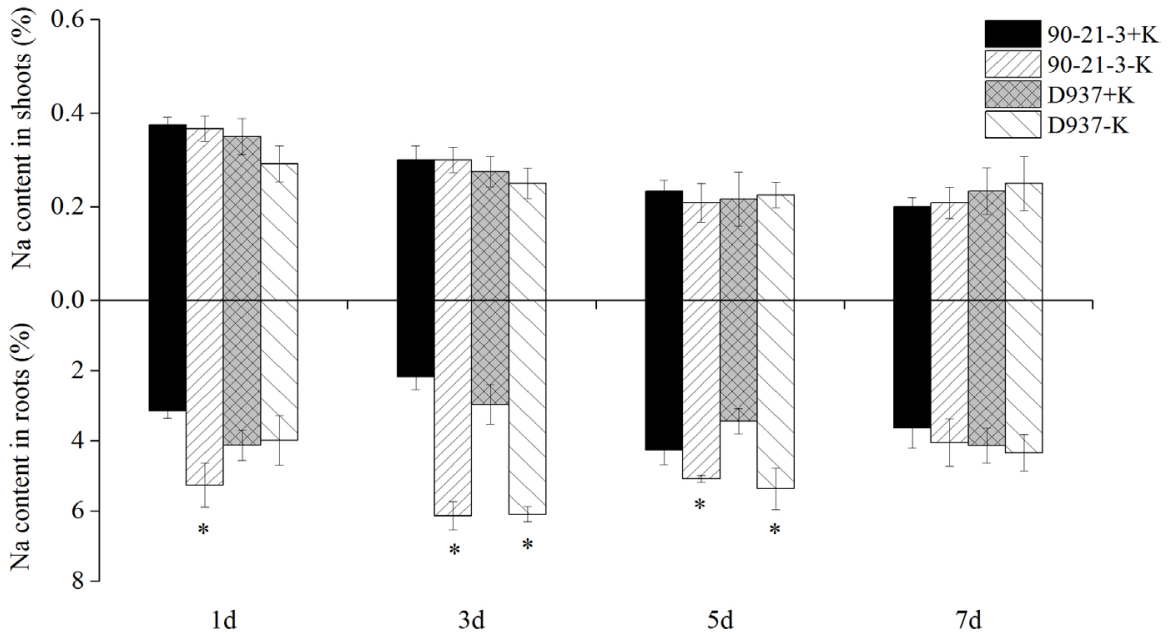

Figure 10. Effect of potassium deficiency on $\mathrm{Na}$ content of different maize genotypes.

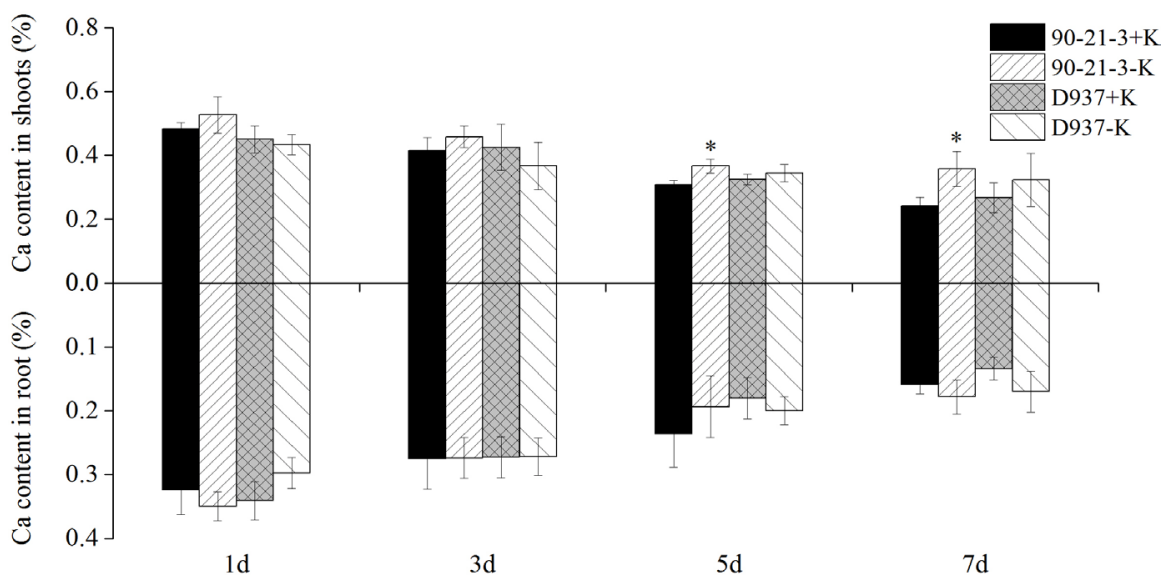

Figure 11. Effect of potassium deficiency on Ca content of different maize genotypes.

changed in shoot of D937 although little increase.

\section{Discussion}

Potassium is a necessary nutrient element for crop growth and development. However, more than $90 \%-98 \%$ is in the combination state although abundant in soil, useless for root system. Due to the irrational fertilization and compound index, the available potassium in soil is decreasing and more seriously, which resulted in $\mathrm{K}$ deficiency area around rhizosphere and inhibiting growth. However, root system has high plasticity by adjusting root configuration and activity to make adaptive changes to promoted ability of absorption for nutrients around the root.

Low potassium stress could reduce the activity of enzyme and nitrogen metabolism related enzymes, and influence the synthesis and accumulation of plant matter [23] [24] [25]. Hell and Mendel (2010) found that the transport of photosynthesis products from the leaves to the roots was hindered under $\mathrm{K}$ deficiency, resulting in a decrease in the accumulation of roots [26]. In the current 
study, the growth of two maize were inhibited, and more reduction in shoots than roots. The results were in accordance with study of Jordan-Meille and Pellerin (2008) [27]. The growth was more depressed with the time of K deficiency, and the R/S ratio was increased. It suggested that the growth was inhibited under $\mathrm{K}$ deficiency, but leaves in 90-21-3 could give priority to the distribution of photosynthetic products to the root system, which promoted the growth of the root system to a certain extent [28].

Root is the major actively organ that absorption and synthesis, and its state and vitality level play an important role in crop growth and nutrient uptake [29]. The root configuration could be adjusted to response the stress for the absorption of nutrients. Crops could promote the absorption of $\mathrm{K}^{+}$through different physiological mechanisms when limiting factor is $\mathrm{K}^{+}$. Epstein et al. (1963) found that the root of barley was promoted by increasing the high affinity potassium transporter under low potassium stress and promoting the transmembrane absorption of $\mathrm{K}^{+}$[30]. Hafsi et al. (2011) found that the root was able to promote the uptake of potassium by increasing length and surface [31]. It was found that root length, root surface area, root diameter and root volume of 90-21-3 and D937 were decreased under $\mathrm{K}$ deficiency. The results were same as Long et al. (2017) that studied for Fe deficiency [32]. In the study, largely reduction of total root length and surface in D937 were displayed under $\mathrm{K}$ deficiency stress, and hardly in 90-21-3. By analyzing the morphological of different diameters, the growth of fine root in D937 was inhibited by K deficiency, which showed a significant decrease in the length and surface area. The fine root is the main part for nutrient absorption, and easily to produce the high gradient, which could effectively promote the absorption of nutrients from rhizosphere [33].

The root activity is commonly regarded as importantly physiological metabolism of root system, indicating absorption ability of root system in soil. Due to higher root activity, crops still could obtain adequate nutrient to maintain development and growth in spite of nutrition deficiency in soil [34]. In the study, the root activity of 90-21-3 and D937 were promoted and higher activity in 90-21-3 than D937 under K deficiency. It suggested that 90-21-3 could be able to increase root activity and get more nutrients from rhizosphere.

Potassium was interrelationship with various nutrient elements in plants [13]. $\mathrm{N}$ is the main constituent of protein, as well as chlorophyll. The significantly synthetic process that nitrogen assimilation was impeded due to the reduction in the activities of important nitrogen metabolism enzymes by $\mathrm{K}$ deficiency, involved nitrate reductase, glutamate dehydrogenase, glutamate synthase, etc. [24]. However, Høgh-Jensen (2003) observed that little affect to accumulate for $\mathrm{N}$ under $\mathrm{K}$ deficiency [35]. But, Wang et al. reported that more accumulated in shoot and root of rice under $\mathrm{K}$ deficiency and increased $\mathrm{N} / \mathrm{K}$ ratio [14]. In our study, the nitrogen was accumulated in shoots, and no effect on root. It may be the result of the "enrichment effect" caused by the inhibition of growth of shoots. Phosphorus is mainly in phospholipids and nuclear proteins, and com- 
posing of the protoplasm and nucleus. Meanwhile, it directly regulated the process of synthesis, transport and decomposition of carbohydrates in plants. In the present study, $\mathrm{K}$ deficiency resulted in significantly less $\mathrm{P}$ accumulation in root, but no affect on shoots. The results were same as the study of Zhang et al. (2015) [36].

The concentration of $\mathrm{K}^{+}$in cells was decreased by potassium deficiency, but other cations could be transferred into cytoplasm to promote osmotic potential [37] [38]. The presence of $\mathrm{Na}^{+}$and $\mathrm{Ca}^{2+}$ in cytoplasm is important in alleviating the effects of $\mathrm{K}$ deficiency. And the function of $\mathrm{Na}^{+}$and $\mathrm{Ca}^{2+}$ substituted for $\mathrm{K}^{+}$ in process of osmotic regulation has been reported. In the present study, the $\mathrm{K}^{+}$ in roots and shoots was rapidly decreased. Compared with the controls, the $\mathrm{K}^{+}$of roots in 90-21-3 was more sensitively decreased than D937, and insensitively in shoots than D937. It suggested that 90-21-3 could promote the transportation of the carbohydrate for growth and development by transferring more $\mathrm{K}^{+}$from root system to shoot. The decrease of $\mathrm{K}^{+}$concentration in root cells led to an increase in osmosis potential, resulting in osmotic stress. But, the accumulation of $\mathrm{Na}^{+}$and $\mathrm{Ca}^{2+}$ could be beneficial to enhance cell osmotic regulation and stabilize cell structure and function in some non-specific functions [13]. In the present study, $\mathrm{K}$ deficiency promoted the accumulation of $\mathrm{Na}^{+}$in the root of 90-21-3 and D937, and little effect on shoot. The accumulation of $\mathrm{Na}^{+}$and $\mathrm{Ca}^{2+}$ in the vacuoles could effectively alleviate the symptoms of potassium deficiency, and not altered the activity of potassium specificity enzyme [39]. Distinctly, 90-21-3 was more sensitive to $\mathrm{Na}^{+}$than $\mathrm{D} 937$ that rapidly accumulated, which compensate for the osmotic stress caused by the decrease of $\mathrm{K}^{+}$in roots. Meanwhile, $\mathrm{Ca}^{2+}$ in shoots of 90-21-3 was largely accumulated under $\mathrm{K}$ deficiency. $\mathrm{Ca}^{2+}$ was able to regulate the CBL4-CIPK6 to activate $\mathrm{K}^{+}$channel AKT2 to accumulate more $\mathrm{K}^{+}$ to leaves [40]. Therefore, the increased $\mathrm{Ca}^{2+}$ in shoots of 90-21-3 not only maintains the osmotic potential, but also promoted the transport and accumulation of $\mathrm{K}^{+}$in shoots from root system.

\section{Conclusion}

In conclusion, $\mathrm{K}$ deficiency led to inhibit the growth of 90-21-3 and D937, more seriously in shoots than roots. The total root length and surface area, especially the fine root, were significantly reduced under $\mathrm{K}$ deficiency. Compared with D937, little reduction in root length and surface area in 90-21-3 was found under $\mathrm{K}$ deficiency, and significantly increased in root activity. $\mathrm{K}^{+}$content in shoots and roots was significantly decreased due to the $\mathrm{K}$ deficiency, but accumulated $\mathrm{Na}^{+}$in roots and $\mathrm{Ca}^{2+}$ in shoots. The 90-21-3 was able to increase the $\mathrm{K}^{+}$in shoots that promoted the transport of carbohydrates to the root system. At the same time, the more accumulation of $\mathrm{Na}^{+}$and $\mathrm{Ca}^{2+}$ in the root system not only effectively alleviated the osmotic stress caused by decreased $\mathrm{K}^{+}$, but also promoted the absorption of $\mathrm{K}^{+}$in root. It may be a response mechanism for short-term $\mathrm{K}$ deficiency by maintaining large root system, increasing root activ- 
ity and adjusting nutrient absorption.

\section{Acknowledgements}

The work was financially supported by the National Natural Science Foundation of China (31771725, 31301259) and the Science and Technology Project for Crop High Yield of China (2013BAD07B03).

\section{References}

[1] Amtmann, A., Hammond, J.P., Armengaud, P. and White, P.J. (2005) Nutrient Sensing and Signalling in Plants: Potassium and Phosphorus. Advances in Botanical Research, 43, 209-257. https://doi.org/10.1016/S0065-2296(05)43005-0

[2] Pettigrew, W.T. (2008) Potassium Influences on Yield and Quality Production for Maize, Wheat, Soybean and Cotton. Physiologia Plantarum, 1339, 670-681. https://doi.org/10.1111/j.1399-3054.2008.01073.x

[3] Wu, L.Q., Wu, L., Cui, Z.L., Chen, X.P. and Zhang, F.S. (2015) Basic NPK Fertilizer Recommendation and Fertilizer Formula for Maize Production Regions in China. Acta Pedologica Sinca, 52, 802-817. (In Chinese)

[4] Tang, J.C. and Cao, M.J. (2001) The Advance in Tolerating Low Potassium of Crops. Journal of Shenyang Agricultural University, 32, 382-385. (In Chinese)

[5] Hu, W., Lv, X., Yang, J., Chen, B., Zhao, W., Meng, Y., Wang, Y., Zhou, Z. and Oosterhuis, D.M. (2016) Effects of Potassium Deficiency on Antioxidant Metabolism Related to Leaf Senescence in Cotton (Gossypium hirsutum L.). Field Crops Research, 191, 139-149. https://doi.org/10.1016/j.fcr.2016.02.025

[6] Hao, S.Y., Jiang, C.C., Wang, X.L., Xia, Y. and Chen, F. (2011) Differences of Potassium Efficiency Characteristics and Root Morphology between Two Cotton Genotypes. Acta Agronomica Sinica, 37, 2094-2098. (In Chinese) https://doi.org/10.3724/SP.J.1006.2011.02094

[7] Sattelmacher, B., Horst, W.J. and Becker, H.C. (1994) Factors that Contribute to Genetic Variation for Nutrient Efficiency of Crop Plants. Journal of Plant Nutrition \& Soil Science, 157, 215-224. https://doi.org/10.1002/jpln.19941570309

[8] Wu, P.F. and Ma, X.Q. (2009) Research Advances in the Mechanism of High Nutrient Use Efficiency in Plants. Acta Ecologica Sinica, 29, 427-437. (In Chinese)

[9] Chen, Z., Yi, X., Chen, F.J., Mi, G.H., Tian, P. and Qi, H. (2017) Differential Response of Maize Roots to Heterogeneous Local Nitrogen and Phosphorus Supply and Genotypic Differences. Journal of Plant Nutrition and Fertilizer, 23, 83-90. (In Chinese)

[10] Yang, X.E., Liu, J.X., Wang, W.M., Li, H., Luo, A.C., Ye, Z.Q. and Yang, Y. (2003) Genotypic Differences and Some Associated Plant Traits in Potassium Internal Use Efficiency of Lowland Rice (Oryza sativa L.). Nutrient Cycling in Agroecosystems, 67, 273-282. https://doi.org/10.1023/B:FRES.0000003665.90952.0c

[11] Zhang, Z.Y., Wang, Q.L., Li, Z.H., Duan, L.S. and Tian, X.L. (2009) Effect of Potassium Deficiency on Root Growth of Cotton (Gossypium hirsutum L.) Seedlings and Its Physiological Mechanisms Involved. Acta Agronomica Sinica, 35, 718-723. https://doi.org/10.3724/SP.J.1006.2009.00718

[12] Sullivan, W.M., Jiang, Z.C. and Hull R.J. (2000) Root Morphology and Its Relationship with Nitrate Uptake in Kentucky Bluegrass. Crop Science, 40, 765-772. https://doi.org/10.2135/cropsci2000.403765x 
[13] Daliparthy, J., Barker, A.V. and Mondal, S.S. (1994) Potassium Fractions with Other Nutrients in Crops: A Review Focusing on the Tropics. Journal of Plant Nutrition, 17, 1859-1886. https://doi.org/10.1080/01904169409364852

[14] Wang, W.M., Yang, X.E., Li, H. and Wei, Y.Z. (2003) Effect of Low Potassium Stress on the Nutrient Uptake and Distribution of Two Rice Varieties with Different Potassium Sensitivity. Chinese Journal of Rice Science, 17, 52-56. (In Chinese)

[15] Li, L. and Luan, S. (2006) $\mathrm{A} \mathrm{Ca}^{2+}$ Signaling Pathway Regulates a $\mathrm{K}^{+}$Channel for Low-K Response in Arabidopsis. Proceedings of the National Academy of Sciences of the United States of America, 103, 12625-1263. https://doi.org/10.1073/pnas.0605129103

[16] Caballero, F., Botella, M.A., Rubio, L., Fernández, J.A., Martínez, V. and Rubio, F. (2012) $\mathrm{A} \mathrm{Ca}^{2+}$-Sensitive System Mediates Low-Affinity $\mathrm{K}^{+}$Uptake in the Absence of AKT1 in Arabidopsis Plants. Plant \& Cell Physiology, 53, 1249-1259. https://doi.org/10.1093/pcp/pcs140

[17] Wang, X.P., Chen, L.M., Liu, W.X., Wang, F.L., Zhou, Y., Zhang, Z., Wu, W.H. and Wang, Q. (2016) AtKC1 and CIPK23 Synergistically Modulate AKT1-Mediated Low Potassium Stress Responses in Arabidopsis. Plant Physiology, 170, 2264-2277. https://doi.org/10.1104/pp.15.01493

[18] Cao, M.J., Yu, H.Q., Yan, H.K. and Jiang, C.J. (2007) Difference in Tolerance to Potassium Deficiency between Two Maize Inbred Lines. Plant Production Science, 10, 42-46. https://doi.org/10.1626/pps.10.42

[19] Luo, H.H., Zhang, Y.L. and Zhang, W.F. (2016) Effects of Water Stress and Rewatering on Photosynthesis, Root Activity, and Yield of Cotton with Drip Irrigation under Mulch. Photosynthetica, 54, 65-73. https://doi.org/10.1007/s11099-015-0165-7

[20] Xu, C., Xia, B.C., Feng, J. and Lin, X.F. (2007) Response of Maize (Zea mays L.) Root Morphology to Cd and Pyrene Contamination in Soil. Ecology and Environment, 16, 771-774. (In Chinese)

[21] Bao, S.D. (2005) Analysis of Soil Agricultural Chemistry. 3rd Edition, China Agriculture Press, Beijing, 263-271. (In Chinese)

[22] Graham, R.D., Gregorio, G., Goode, J. and Chadwick, D. (2001) Breeding for Nutritional Characteristics in Cereals. Symposium on Rice Biotechnology, 236, 205-218.

[23] Kanai, S. and Fujita, K. (2007) Depression of Sink Activity Precedes the Inhibition of Biomass Production in Tomato Plants Subjected to Potassium Deficiency Stress. Journal of Experimental Botany, 58, 2917-2928. https://doi.org/10.1093/jxb/erm149

[24] Qu, C.X., Liu, C., Ze, Y.G., Gong, X.L., Hong, M.M., Wang, L. and Hong, F.S. (2011) Inhibition of Nitrogen and Photosynthetic Carbon Assimilation of Maize Seedlings by Exposure to a Combination of Salt Stress and Potassium-Deficient Stress. Biological Trace Element Research, 144, 1159-1174. https://doi.org/10.1007/s12011-011-9037-6

[25] Wang, X.G., Zhao, X.H., Jiang, C.J., Li, C.H., Cong, S., Wu, D., Chen, Y.Q., Yu, H.Q. and Wang, C.Y. (2015) Effects of Potassium Deficiency on Photosynthesis and Photoprotection Mechanisms in Soybean (Glycine max (L.) Merr.). Journal of Integrative Agriculture, 14, 856-863. https://doi.org/10.1016/S2095-3119(14)60848-0

[26] Hell, R. and Mendel, R.R. (2010) Cell Biology of Metals and Nutrients. Springer Ebooks, 17, 209-246. https://doi.org/10.1007/978-3-642-10613-2

[27] Jordan, M.L. and Pellerin, S. (2008) Shoot and Root Growth of Hydroponic Maize (Zea mays L.) as Influenced by K Deficiency. Plant \& Soil, 304, 157-168. 
https://doi.org/10.1007/s11104-007-9534-8

[28] Singh, P. and Blanke, M.M. (2000) Deficiency of Potassium But Not Phosphorus Enhances Root Respiration. Plant Growth Regulation, 32, 77-81.

https://doi.org/10.1007/s11104-007-9534-8

[29] Xu, G.H., Bao, S.D., Yang, J.P. and W.M. (1995) The Relationship between Potassium Absorbtion Ability and Root Parameters of Different Crops. Journal of Nanjing Agricultural University, 18, 49-52. (In Chinese)

[30] Epstein, E., Rains, D.W. and Elzam, O.E. (1963) Resolution of Dual Mechanisms of Potassium Absorption by Barley Roots. Proceedings of the National Academy of Sciences of the United States of America, 49, 684-692.

https://doi.org/10.1073/pnas.49.5.684

[31] Hafsi, C., Atia, A., Lakhdar, A., Debez, A. and Abdelly, C. (2011) Differential Responses in Potassium Absorption and Use Efficiencies in the Halophytes Catapodium rigidum and Hordeum maritimum to Various Potassium Concentrations in the Medium. Plant Production Science, 14, 135-140.

https://doi.org/10.1626/pps.14.135

[32] Long, W.J., Gu, T., Wan, N.X., Peng, B.Y., Kong, F.L. and Yuan, J.C. (2017) Effect of Low Iron Stress on Root Growth and Iron Uptake and Utilization of Different Maize Cultivars at Seedling Stage. Chinese Journal of Eco-Agriculture, 25, 1163-1172. (In Chinese)

[33] Jungk, A. (2015) Root Hairs and the Acquisition of Plant Nutrients from Soil. Journal of Plant Nutrition \& Soil Science, 164, 121-129. https://doi.org/10.1002/1522-2624(200104)164:2<121::AID-JPLN121>3.0.CO;2-6

[34] Lynch, J. (1995) Root Architecture and Plant Productivity. Plant Physiology, 109, 7-13. https://doi.org/10.1104/pp.109.1.7

[35] Høgh-Jensen, H. (2003) The Effect of Potassium Deficiency on Growth and $\mathrm{N}_{2}$-Fixation in Trifolium repens. Physiologia Plantarum, 119, 440-449. https://doi.org/10.1034/j.1399-3054.2003.00189.x

[36] Zhang, A.Q., Sechenchogt, Wang, L.H. and Wang, Y.N. (2015) Effects of K Stress on Growth and P Uptake of Different Genotypes Maize. Hubei Agricultural Sciences, 54, 292-295. (In Chinese)

[37] Anschütz, U., Becker, D. and Shabala, S. (2014) Going beyond Nutrition: Regulation of Potassium Homoeostasis as a Common Denominator of Plant Adaptive Responses to Environment. Journal of Plant Physiology, 171, 670-687. https://doi.org/10.1016/j.jplph.2014.01.009

[38] Benito, B., Haro, R., Amtmann, A., Cuin, T.A. and Dreyer, I. (2014) The Twins K ${ }^{+}$ and $\mathrm{Na}^{+}$in Plants. Journal of Plant Physiology, 171, 723-731. https://doi.org/10.1016/j.jplph.2013.10.014

[39] Zörb, C., Senbayram, M. and Peiter, E. (2014) Potassium in Agriculture-Status and Perspectives. Journal of Plant Physiology, 171, 656-669.

https://doi.org/10.1016/j.jplph.2013.08.008

[40] Katrin, H., François, P., Christian, E., Pawel, G., Kenji, H., Claire, C., Jan, N.O., Benoît, L., Ingo, D., Jean-Baptiste, T. and Jörg, K. (2011) Calcium-Dependent Modulation and Plasma Membrane Targeting of the AKT2 Potassium Channel by the CBL4/CIPK6 Calcium Sensor/Protein Kinase Complex. Cell Research, 21, 1116-1130. https://doi.org/10.1038/cr.2011.50 